\title{
Open Innovation in Public Authorities
}

\author{
Diana Chronéer ${ }^{1}$, Mari Runardotter ${ }^{2}$ \\ ${ }^{1}$ Department of Computer Science, Electrical and Space Engineering, Luleå University of Technology, \\ Diana.Chroneer@ltu.se I \\ ${ }^{2}$ Department of Computer Science, Electrical and Space Engineering, Luleå University of Technology, \\ Mari.Runardotter@ltu.se
}

\begin{abstract}
Today openness is regarded the main driver to achieve organisational and societal growth. This openness will happen, it is believed, through the means of open data. There are high expectations of what the realization of open data will lead to, such as transparent democracy and administration, increased business competitiveness, new economic opportunities and help in tackling societal and environmental challenges.

In this paper we explore and discuss the need for a roadmap to achieve openness in public authorities, as well as mechanisms of governance, and what is needed in order for a public authority to become innovative. We conclude that there is a range of issues that public authorities need to consider, if the openness initiative is to succeed, from how to redesign organisational roles, administrative tasks, control systems and decision making to organisational culture.
\end{abstract}

Key words: Open government, open governance, open innovation, open data, management.

(C) 2015 Diana Chronéer et al. This is an Open Access article distributed under the terms of the Creative Commons Attribution-NonCommercial 4.0 International License (http://creativecommons.org/licenses/by-nc/4.0/), permitting all non-commercial use, distribution, and reproduction in any medium, provided the original work is properly cited. http://dx.doi.org/10.15626/dirc.2015.05 


\section{Introduction}

'Open' is the current buzz-word, and the intention with openness is to encourage organisational and societal growth through innovation (Chesbrough 2011; Feller et al. 2011; Janssen et al. 2012; COM 2010; PSI directive 2003; 2013). By now the ideas of openness are spread and many organisations, both public and private, are actively implementing policies for openness, mainly with an emphasis on open data. Hence, openness and open data are the key concepts in the on-going transformation of digital public services (Lathrop \& Ruma 2010).

The intentions and expected outcomes with openness are often expressed in various open data initiatives, often found in policy documents and other publications. The European Commission (EC) foresees that open data will lead to: (1) a transparent democracy and administration in public authorities; (2) increased business competitiveness; (3) new economic opportunities (through innovation and growth); (4) help in tackling societal and environmental challenges; and (5) increased scientific progress (PSI directive 2003; 2013). Hitherto there is not much reported on the open policy's progress, consequently it is not clear what the exact impacts and benefits of open data actually are (Huijboom \& Van den Broek 2011; Conradie et al. 2012). Thus, relevant issues are for example how to create the open government, what open data strategy is suitable for governments and how come that some governments succeed while others do not? (Huijboom \& Van den Broek 2011).

Today open data is on the political agenda, and there are defined strategies for open data at regional government levels, but research has shown that individual authorities are often reluctant to put these policies into practice (Huijboom and Van den Broek 2011). For example, Swedish authorities show a protective culture, their personnel wants to be in control, thus there is a negative attitude towards open data (SOU 2014:10). The Commission acknowledges that "where eGovernment services are offered, the majority of EU citizens are reluctant to use them" (COM 2010, p. 3). Hence, the open data and open government policies are not yet implemented, and not yet accepted. So, how will openness in public organisations become realized?

The purpose of this paper is to explore and discuss the need for a roadmap to achieve openness in the public sector and accordingly, to explore the mechanisms of needed governance. We argue that governance is important to explore, in order to develop suitable governance mechanisms in the public organisations. It is notable in the research literature that the concept of governance and its meaning has been focussed lately. For instance, research on project management show that the use of projects in organisations has evolved towards becoming a strategic means which actually transform organisations (Biesenthal \& Wilden, 2014) and that organisations, and the projects they govern, must deal with challenges posed by uncertainty in both ecological, social as well as economic sustainability (Pitsis et al., 2014). 


\section{Open Government}

There are many goals for open government (or Government 2.0, electronic government, or e-government) and its development, such as transparency, participation and collaboration (Chun et al. 2010), and the creation of smart, sustainable and innovative government (COM 2010). Hence, open government targets democratisation, innovation and growth. It is related to open data, since open data is viewed as the engine for innovation, growth and transparent government (COM 2011). Open data is defined as freely available data that anyone can use and republish as they wish, unless the data is restricted by control mechanisms, such as privacy, copyright, or patents (Auer et al. 2007; Janssen et al. 2012).

The underlying intention with open government is to ensure that citizens are provided insight into public administration and affairs. However, Lathrop \& $\mathrm{Ru}-$ ma (2010) argue that the intentions behind open government evolve and the policy is now also addressing citizens' participation in governmental procedures. For the government the expectations are improved communication and operations across different levels of government, as well as increased efficiency and accountability (ibid.).

Within the EU it is the PSI directive that in many parts constitutes the roadmap. In the 2003 version of the directive, emphasis was on economic growth through the publishing of open data, but also a wish to increase knowledge among citizens (PSI directive 2003). By now, open data is expected to contribute to transparent democracies, business competitiveness, economic opportunities and tackling societal and environmental challenges, as well as scientific progress (PSI directive 2003; 2013).

How to implement openness differs among governments. Huijboom and Van den Broek (2011) report from an international comparison of strategies for open data involving Australia, Denmark, Spain, United Kingdom and United States, and these countries used education and training, voluntary approaches, economic incentives and legislation/control when implementing open data policies. Huijboom and Van den Broek (2011) also found that good examples from those at the front is helpful; political leadership; initiatives taken by regions, citizens or the market; emerging technologies, European legislation; and finally experts and communities that have the power to put open data on the political agenda. There are also phenomena that hinder the implementation, of which a closed government culture is regarded to be the greatest barrier. In addition, privacy legislation; data of limited quality; limited user friendliness and information overload; lack of standardization of open data policy and security threats are examples of other hindrances.

Where the PSI Directive is mainly focussing on open data and open information, the US Open Government Directive explicitly aims at open government. US governmental authorities are expected to post their open government plans, with detailed descriptions of what steps and actions the authority is planning in 
order to improve transparency. They are also expected to provide links to websites, making it possible for citizens to engage in participatory processes (McDermott 2010). Nevertheless, Ganapati and Reddick (2010) report from an online survey answered by 24 Chief Information Officers (CIO) across the state governments in the US, and their findings suggest that the implementation of open government differs. The CIOs reasoned that a high level of open government is reached, but when they were asked about transparency, participation and collaboration, they hesitated. Of these it was first and foremost transparency that was implemented, according to the CIOs, while there were less success with participation and collaboration. Altogether, there is a similar situation in Australia, the EU and the US, hence we state that open government is on its way, but there is a long way ahead. As Huijboom and Van den Broek (2011) put it, there is so far no evidence of the economic impact of open data, nor can the causal relation between open data and increased democracy be established.

This indicates that there are a number of dilemmas that need to be addressed for the open government to succeed, which all stems from the fundamental question of how to actually handle the open policy implementation. Is there a thorough understanding of what this openness actually implies? Is it clear who should take responsibility, and for what? How to actually reach transparency, citizen's participation and democratization?

\section{Governance of openness}

The dilemma we identify regarding governance of openness relates to the traditional way of governing public authorities. Governance can be defined as a government's ability to make and enforce rules, and to deliver services, regardless of whether that government is democratic or not (Fukuyama 2013). Also, governance is about the performance of so called agents in carrying out the wishes of stakeholders (not only about the goals that stakeholders set) (Benz \& Frey 2007). Governance is thus about execution, the division of power within firms, rules of succession in top positions, and institutionalized competition in core areas of governance (Benz \& Frey 2007). The concept of governance can also be viewed as 'unilateral governance' (the firm's controlling authority) that deals with formal controls and mechanisms that are put in place to manage the unilateral relationships. For example, personnel involved in the day-to-day management of the relationship would have rules for information sharing and tools to monitor and limit knowledge flows. 'Bilateral governance' on the contrary, is based on mutual relational norms and has an emphasis on trust, relational norms, and mutuality in the relationship (Mohr \& Sengupta 2002). In its broadest definition, good governance can be related to how individuals, groups, organisations, societies, and nation states are held accountable not only for outcomes but also ethical behaviours (Pitsis et al., 2014). 
The importance of governance is shown in recent project management research literature (e.g. Biesenthal and Wilden, 2014). Nielsen (2010) states that project governance represent a higher-level structure; defining processes and structures to govern and manage strategic objectives. This is also observed by Pitsis et al., (2014), who claim that governance matters, i.e. project and program governance has the potential to make a major scholarly and practical contribution to governance practice. Thus a major challenge for leadership is to ensure that projects align with strategic imperatives and changing contexts of action that might redefine these imperatives (Meskendahl, 2010).

Today, the role of government is being transformed from direct service provider to generator of public value, but in the twentieth century, rigid, hierarchical government bureaucracy was the main organisational model used to deliver public services and realize public policy goals (Goldsmith \& Eggers 2004). Thus, for a long time the focus has been on stability where the purpose of actions tends to be execution of regulations. Managers in bureaucratises tend to be conservative and cautious, and use strict guidelines to direct behaviours (Gregory et al. 2009). Since the role of government has transformed from direct service provider to generator of public value, with different benefits - flexibility, speed, innovation, citizen focus, governments must create means of how to manage networks to get the results citizens expect. Inflexible bureaucratic systems that operate with control procedures, constructed work restrictions, and "inward-looking" cultures and operational models do no longer fit to address problems that often concern external parties i.e. that go beyond organisational boundaries (Goldsmith \& Eggers 2004). Therefore, we argue that there is a need of changed governance mechanisms that support a flexible and "outward-looking" culture since openness builds on the idea of interaction, communication and collaboration with external groups found outside the organisation. Central for the openness initiative are the understandings of how open innovation and networked governance can be of support.

\section{The dilemma of openness}

The term "openness" has been frequently discussed in the open innovation literature (e.g. Laursen \& Salter 2006; Chesbrough \& Appleygard 2007; Enkel et al. 2009; Dahlander \& Gann 2010). In defining openness, Chesbrough (2003, p. XXIV) claims that "open innovation is a paradigm that assumes that firms can and should use external ideas as well as internal ideas, and internal and external paths to market, as firms look to advance their technology". We argue that the dilemma of openness relates to the absence of clarity regarding what mechanisms are needed in the public sector to enhance open innovation and thus supportive governance. Lee et al. (2012) summarise that a growing number of public sector organisations are now reaching out for good ideas and new ways to deliver public services from across the world. Instead of innovating all by themselves, authorities attempt to make the greatest use of external knowledge sources to add public val-

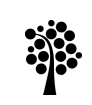

Papers from the 18th annual Dilemmas International Research Conference 
ue, something that, according to Lee et al. (2012), has resulted in a widespread restructuring of organisational forms within the public sector. Some of the challenges of becoming a 'value provider' are related to: structure, government's organisational, management, and personnel systems (designed to operate within a hierarchical model of government). Because of the hierarchical decision-making structure, inflexible bureaucracies tend to react slowly to new situations and opportunities. In order to become a provider of public value, a form of 'public management' of required, which is very different from what governments and their citizens have become accustomed to over the past hundred years.

As an alternative to the paradigms discussed above, some public sector organisations have adopted networked forms of governance (Lee et al. 2012), i.e. citizen-centred governance based on emerging patterns of governance and service delivery (Hartley 2005). Lee et al. (2010) point out that one important characteristic of networked governance is that the public is considered co-producers of service and innovation. Also, an increasing number of governments are developing so called open innovation policies to bring together external partners with specific capabilities and integrate their contributions (Lee et al. 2012). Lee et al. (2012) argue that the notion of applying the open innovation paradigm in the public sector is not really new and that the traditional government model has been changed toward a network model which involves establishing a network of partners and empowering them. For an organisation, regardless whether public or private, some things must be in place if they are to open up their information. These challenges are of different nature, and range from technical (infrastructures and interoperability) issues, via common policies (around objectives, strategies and methods), to administrative and organisational challenge (Runardotter et al. 2011). In this paper we are leaving the technical aspects aside, since they are not always the main problem. We argue that there is a great deal of organisational challenges to consider and work with for a public manager, e.g. how to handle the open data policy implementation (Huijboom \& Van den Broek 2011), dealing with lack of knowledge (Halonen 2012), area of responsibility, etc.

Our proposition is that in order to become open and transparent in its deepest sense, an organisation must pay attention to its processes and routines, governance, management, and strategies, but also to its organisational culture and values as suggested by Alvesson \& Sveningsson (2008). Firstly, there is need of knowledge on what facilitates/hinders the development of open organisations, and how to manage and steer a policy implementation process towards openness, as well as how to manage and steer the open organisation in the long run. Secondly, there is a need of suitable governance mechanisms that build a relationship with citizens so that openness can be achieved. We claim that different openness initiatives require a diversity of approaches, and that there is need of 'open management' guidance appropriate for different contexts. As Rahman (2007) states, organisations need 'good governance', and both organisational and technical 
knowledge for to be able to implement policies and initiatives that lead to the open e-society. Good governance should also adhere to principles such as working toward greater openness; participation; accountability; effectiveness, and coherence (COM 2001).

\section{Concluding remarks}

The purpose of this paper was to explore and discuss the roadmap of achieving openness in the public sector and hence to explore the mechanisms of needed governance. The openness initiative in the public sector is, as we have showed above, neither entirely implemented in public authorities, nor fully accepted by citizens. This indicates that there are obstacles along the way. Managers at different levels are stuck in the middle and expected to carry out a policy which they might not have adequate means and guidelines for to accomplish. Hence, we argue that there is a need of a governance roadmap that will support the change towards openness within public authorities.

We have identified some issues that must be considered for the openness initiative to succeed. A public authority needs to consider whether the policy of openness requires any redesign when it comes to organisational roles, administrative tasks, control systems, and decision making, as well as consider how to become a flexible, innovative and open organisation. All this is to happen within an organisation marked by a certain culture, which is many times distinguished by being hierarchical and bureaucratic. In this kind of organisational culture emphasis is put on internal efficiency, uniformity, coordination and control (Denison \& Spreitzer 1991). Thus, the dilemma is: how will an organisation that focuses on effectiveness based on criterions such as control, stability and efficiency become open, flexible and innovative? Moreover, public authorities are now also expected to collaborate with citizens to a higher degree (i.e. the democratisation objective of open government), which adds further complexity for the public authorities to handle.

In sum, we argue that public authorities need to re-think many parts of their organisation such as organisational roles, with whom to collaborate, and how to share information and knowledge. How to create an organisational culture that supports innovation and openness is also of vital importance.

Since this is a conceptual paper, we argue that future research is needed, in order to strengthen our proposition. First of all, it would beneficial to conduct case studies, and action research to explore both what the current situation looks like in public authorities, and what are the managers' needs, wants and wishes when it comes to open government? It would also be interesting to test and verify our suggestions, in order to be able to provide managerial implications, and thereby establish the concept of 'open management'. These suggestions to investigate mechanisms to development needed processes, routines, change of mind-sets and values, i.e. there is a need of a road map of how to manage openness. We also 
suggest further critical investigation of the concept 'open', and how it is interpreted, experienced and understood among public authorities' personnel as well as among citizens.

\section{References}

Alvesson, M. \& Sveningsson, S., 2008. Förändringsarbete i organisationer - om att utveckla företagskulturer. Malmö: Liber AB.

Auer, S. R., Bizer, C., Kobilarov, G., Lehmann, J., Cyganiak, R. \& Ives, Z., 2007. DBpedia: A Nucleus for a Web of Open Data. In: The Semantic Web. Lecture Notes in Computer Science 4825, 722.

Berners-Lee, T., 2006. Linked Data.

http://www.w3.org/DesignIssues/LinkedData.html [2014-08-11]

Benz, M. \& Frey, B.S., 2007. Corporate Governance: What can we Learn from Public Governance? Academy of Management Review, 32(1), 92-104.

Biesenthal, C. \& Wilden, R., 2014. Multi-level Project Governance: Trends and Opportunities. International Journal of Project Management, 32(8), 12911308

Bizer, C., Heath, T. \& Berners-Lee, T., 2009. Linked Data - The Story So far. http://tomheath.com/papers/bizer-heath-berners-lee-ijswis-linked-data.pdf [2014-08-11]

Chesbrough, H., 2003. Open Innovation: The New Imperative for Creating and Profiting from Technology. Boston, MA: Harvard Business School Press.

Chesbrough H., 2007. Business Model Innovation: It's not just About Technology Anymore. Strategy \& Leadership, 35(6), 12-17.

Chesbrough, H. W., \& Appleyard, M. M., 2007. Open Innovation and Strategy. California Management Review, 50(1), 57-76.

Chesbrough, H., 2011. Open Service Innovation - Rethinking Your Business to Grow and Compete in a New Era. San Fransisco: Jossey-Bass.

Chun, S.A.; Shulman, S.; Sandoval, R. \& Hovy, E., 2010. Government 2.0: Making Connections between Citizens, Data and Government. Information Polity, $15,1-9$.

COM., 2001. 428 final. European Governance - A White Paper.

http://eur-lex.europa.eu/legalcontent/EN/TXT/PDF/?uri=CELEX:52001DC0428\&rid=2 [2014-08-11]

COM., 2010. 743 final COMMUNICATION FROM THE COMMISSION TO THE EUROPEAN PARLIAMENT, THE COUNCIL, THE EUROPEAN ECONOMIC AND SOCIAL COMMITTEE AND THE COMMITTEE OF THE REGIONS The European eGovernment Action Plan 2011-2015. Harnessing ICT to promote smart, sustainable \& innovative Government. http://eur- 
lex.europa.eu/LexUriServ/LexUriServ.do?uri=COM:2010:0743:FIN:EN:PD F [2014-08-13]

COM., 2011. 882 final. Communication from the Commission to the European Parliament, the Council, the European Economic and Social Committee and the Committee of the Regions. Open data. An engine for innovation, growth and transparent government. http://eurlex.europa.eu/LexUriServ/LexUriServ.do?uri=COM:2011:0882:FIN:EN:PD F [2014-08-11]

Conradie, P., Mulder, I. \& Choenni, S., 2012. Rotterdam Open Data: Exploring the release of public sector information through co-creation. Engineering, Technology and Innovation (ICE), 2012 18th International ICE Conference. http://ieeexplore.ieee.org/xpl/articleDetails.jsp?arnumber=6297651 [201408-11]

Dahlander, L. \& Gann, D.M., 2010. How Open is Innovation? Research Policy, 39(6), 699-709.

Denison, D. R. and Spreitzer, G. M., 1991. Organizational Culture and Organizational Development: A Competing Values Approach Research in Organizational Change and Development, Vol. 5, No., pp.1-21.

Enkel, E., Gassman, O. \& Chesbrough, H., 2009. Open R\&D and Open Innovation: Exploring the Phenomenon. $R \& D$ Development, 39(4), 311-316.

Feller, J., Finnegan, P. \& Nilsson, O., 2011. Open Innovation and Public Administration: Transformational Typologies and Business Model Impacts. European Journal of Information Systems, 20, 358-374.

Fukuyama, F., 2013. What Is Governance? Governance, 26(3), 347-368.

Ganapati, S. and Reddick, C., 2012. Open E-government in U.S. State Governments: Survey Evidence from Chief Information Officers. Government Information Quarterly, (29), 115-122.

Goldsmith, S. \& Eggers, W.D., 2004. Governing by Network the New Shape of the Public Sector. Washington, D.C.: Brookings Institution Press.

Gregory, B. T., Harris, S. G., Armenakis, A. A. and Shook, C. L., 2009. Organizational Culture and Effectiveness: A Study of Values, Attitudes, and Organizational Outcomes. Journal of Business Research, Vol. 62, No. 7, pp.673-679.

Halonen, A., 2012. Being Open About Data. Analysis of the UK open data policies and applicability of open data.The Finnish Institute in London. http://assets.finnishinstitute.studiocoucou.com/media/W1siZiIsIjIwMTMvM DEvMzEvMTNfMDNfMTNfNjM1X2JlaW5nXzIwb3Blb18yMGFib3V0Xz IwZGF0YS5wZGYiXV0/being\%2520open\%2520about\%2520data.pdf?sha $=9 \mathrm{~b} 1040 \mathrm{ca}[2014-08-11]$

Hartley, J., 2005. Innovation in governance and public services: past and present. Public Money and Management, 25(1), 27-34. 
Huijboom, N. \& Van den Broek, T., 2011. Open Data: an International Comparison of Strategies. European Journal of ePractice, No. 12, March/April 2011. ISSN: 1988-625X. www.epracticejournal.eu

Janssen, M., Charalabidis, Y. \& Zuiderwijk, A., 2012. Benefits, Adoption Barriers and Myths of Open Data and Open Government. Information Systems Management, 29(4), 258-268.

Lathrop, D. \& Ruma, L., eds., 2010. Open Government - Collaboration, Transarency and Participation in Practice. Sebastopol: O'Reilly Media Inc.

Laursen, K. \& Salter, A., 2006. Open for Innovation: the Role of Openness in Explaining Innovation Performance Among U.K. Manufacturing Firms. Strategic Management Journal, 27(2), 131-150.

Lee, S.M., Hwang, T. \& Choi, D., 2012. Open Innovation in the Public Sector of Leading Countries. Management Decision, 50(1), 147 - 162.

McDermott, P., 2010. Building open government. Government Information Quarterly, 27, 401-413.

Meskendahl, S., 2010. The Influence of Business Strategy on Project Portfolio Management and its Success: A Conceptual Framework. International Journal of Project Management, 28, 807-817.

Mohr,J.J. \& Sengupta, S., 2002. Managing the Paradox of Inter-Firm Learning: The Role of Governance Mechanisms. Journal of Business \& Industrial Marketing, 17(4), 282 - 301.

Nielsen, B.B., 2010. Strategic Fit, Contractual, and Procedural Governance in Alliances. Journal of Business Research, 63, 682-689.

Pattuelli, C.M., Weller, C. \& Szablya, G., 2011. Linked Jazz: An Exploratory Pilot. Proceedings from the International Conference on Dublin Core and Metadata Applications.

Pitsis, T.S., Sankaran, S., Gudergan, S. \& Clegg, S.R., 2014. Governing Projects under Complexity: Theory and Practice in Project Management. International Journal of Project Management, 32, 1285-1290.

Poikola, A., Kola, P. \& Hintikka, K., 2011. Public data. An introduction to opening up information resources. Ministry of Transport and Communications, Finland.

http://www.vinnova.se/PageFiles/181505160/57392397-Public-Data.pdf [2014-02-17]

PSI DIRECTIVE 2003/98/EC. DIRECTIVE 2003/98/EC OF THE EUROPEAN PARLIAMENT AND OF THE COUNCIL of 17 November 2003 on the reuse of public sector information.

http://eur-

lex.europa.eu/LexUriServ/LexUriServ.do?uri=OJ:L:2003:345:0090:0096:E N:PDF [2014-03-14]

PSI DIRECTIVE 2013/37/EU. DIRECTIVE 2013/37/EU OF THE EUROPEAN PARLIAMENT AND OF THE COUNCIL of 26 June 2013 amending Di- 
rective 2003/98/EC on the re-use of public sector information. http://eurlex.europa.eu/LexUriServ/LexUriServ.do?uri=OJ:L:2013:175:0001:0008:E $\mathrm{N}:$ PDF [2014-08-11]

Rahman, H., 2007. E-Government Readiness: from the Design Table to the Grass Roots. Proceedings of the 1st International Conference on Theory and Practice of Electronic Governance. Macao, China, December 2007 ACM International Conference Proceedings Series. Vol. 232, pp. 225-232.

Runardotter, M., Jonsson, Ö., Jóna Eiríksdóttir, H., Pálmadóttir Sighvats, J., Sigurðsson, N., Djupdahl, M., Geber, M., Nurme, B., Aas, K. \& Ruusalepp, R., 2011. Access to Public Information in Government Agencies and Archives. New E-Services for Archives: Results from User and Expert Survey. http://pure.ltu.se/portal/da/publications/access-to-public-information-ingovernment-agencies-and-archives(fd18e3fc-e6a6-414b-89c09159677f57bd).html.

SOU 2014:10. Ett steg vidare - nya regler och åtgärder för att främja vidareutnyttjande av handlingar. Statens offentliga utredningar 2014:10. http://www.regeringen.se/sb/d/18055/a/235091 [2014-03-19]. 